\title{
Hematologic Variation Values of Captive Red-footed Tortoise (Chelonoidis carbonaria) in South Brazil
}

\author{
Bruno Carvalho da Silva Bergamini ${ }^{1}$, Elisandro Oliveira dos Santos ${ }^{2}$, Bárbara Schiller Wartchow ${ }^{3}$, \\ Lilian Heck ${ }^{3}$, Luiza Uhrig ${ }^{4}$, Lygia Karla Sanches Francelino4, Gisele Guiomara Stein ${ }^{4}$, \\ Gustavo Machado ${ }^{5}$ \& Stella de Faria Valle ${ }^{5}$
}

\begin{abstract}
Background: Reference hematological values for chelonians are uncommon, especially those that take account of seasonal variations. While there exists controversy over how climate influences hematological values in different reptile species, the identification of this influence would help with the diagnosis, treatment, and prognosis of diseases that affect these species, often kept as pets. Chelonians are ectotherms and, therefore, intrinsic and extrinsic factors may affect physiological and hematological values, affecting the interpretation of clinical information on these species. The aims of this study were to assess the hematological values of captive red-footed tortoises (Chelonoidis carbonaria) and to check their variation according to the cold and warmer seasons of the year.

Materials, Methods $\&$ Results: Blood samples were collected from nine red-footed tortoises (C. carbonaria) of indeterminate sex and different ages, bred in captivity without control over environmental variables during one year, one each season (summer, fall, winter and spring). A total of 36 samples were considered to study. The colder seasons were collapsed together into one group that holds winter and fall (colds) and the months whit warmer weather spring and summer were grouped as a class called (warm). The complete blood count was performed manually, and medians, maximum values, and minimum values were obtained from the animals in each season of the year. The samples were grouped in "cold" and "warm" classes as above. Repeated measures ANOVA were used in order to compare the influence of climate variation on hematologic variables. For this mater Bonferroni's test was employed as post-hoc analysis. As results, the erythrocytes total count, hemoglobin value, hematocrit, mean corpuscular hemoglobin concentration, absolute numbers of heterophils, eosinophils, basophils, monocytes, and total plasma proteins varied significantly $(P<0.05)$ between colder and warmer seasons. Erythrocyte values yielded significantly higher values in warmer seasons than in the other seasons. The seasonality was verified in erythrocytes total count $(P<0.001)$, hemoglobin value $(P<0.001)$, hematocrit values $(P<0.001)$ and differential white blood cell count $(P<0.001)$.

Discussion: The hematological alterations detected in C. carbonaria were similar observed in similar studies in reptiles species and due to the distinct method and management used and different species, it was not possible to compare the statistical results. In previously studies, as a $C$. carbonaria, the hematological variations between climatic seasons were identified in other reptile species due particular ectothermic metabolism. The variation in total WBC count produced by seasons of the year had already been described in snakes, such as in South American rattlesnakes and in tropical snakes. Changes in metabolic activity may be influence in TPP values in reptiles when season of the year is included as a variable. In hibernating species, the variation in TPP values is attributed to hibernating behavior when the lower food intake led to a decrease in plasma protein levels. In the case of $C$. carbonaria, which does not hibernate, other variables could influence the difference between seasons. All hematological changes observed in studied animals confirm the influence of climate between cold and hot months, given the peculiar metabolism of chelonians. The results point out the importance is to consider the seasonal climate variations in the interpretation of hematological values of $C$. carbonaria under uncontrolled environmental conditions.
\end{abstract}

Keywords: chelonians, climate variation, complete blood count, white blood cell count.

DOI: $10.22456 / 1679-9216.79176$

${ }^{1}$ School of Veterinary Medicine and Animal Science, Universidade Estadual Paulista Júlio de Mesquita Filho (UNESP), Botucatu, SP, Brazil. ${ }^{2}$ Canoas Local Zoo, Canoas, RS, Brazil. ${ }^{3}$ School of Veterinary Medicine, Federal University of Rio Grande do Sul (UFRGS), Porto Alegre, RS. ${ }^{4}$ Self-employed Veterinary doctor. ${ }^{5}$ Department of Veterinary Clinical Pathology, School of Veterinary Medicine, UFRGS, Porto Alegre. CORRESPONDENCE: S.F. Valle [stella.valle@ ufrgs.br - Tel.: +55 (51) 3308-6099]. Laboratório de Análises Clínicas Veterinárias (LACVet) - UFRGS. Av. Bento Gonçalves n. 9090. Bairro Agronomia. CEP 91540-000 Porto Alegre, RS, Brazil. 


\section{INTRODUCTION}

Tortoises (order Testudinata, family Testudinidae, genus Chelonoidis) are terrestrial, non-hibernating chelonians with small-sized bodies, heavy shells, and cylindrical and sturdy limbs. There are three tortoise species in Brazil: red-footed tortoise (Chelonoidis carbonaria), yellow-footed tortoise ( $C$. denticulata) and Chaco tortoise $(C$. chilensis). The first two are distributed all over Brazil, while the third one occurs only in southern Brazil. They are relatively popular as pets and, for that reason; there is a growing demand for information on the clinical and laboratory values of these species $[1,6]$.

Species, age, gender, and health status are intrinsic factors that, when associated with environmental and nutritional management, captive care, and climate, may influence both qualitatively and quantitatively blood components, that may affect reference values or hinder the distinction between pathological processes and physiological changes in these animals $[3,9,12,14]$.

Seasonal variation of hematological values has already been reported for other orders, as that of snakes $[2,7,15]$, for other chelonian species $[4,5,13,16]$ and for Testudines [10] under natural conditions and in captivity. Most studies suggest taking this extrinsic variable into account in the establishment of reference values and in the interpretation of RBC (red blood cell) count results of these species.

The present study was conducted because of the need of determining the influence of climate variation on captive-bred chelonians not submitted to environmental control (temperature and moisture) and also because there is a dearth of information on hematological values of Chelonoidis carbonaria.

\section{MATERIALS AND METHODS}

\section{Animals}

All sampled animals belonged to Canoas local zoo (Canoas, Rio Grande do Sul, Brazil, 29'55'01.4”'S $51^{\circ} 10^{\prime} 12.4$ 'O), where temperatures varied as follows: minimum of $14^{\circ} \mathrm{C}$ and maximum of $22^{\circ} \mathrm{C}$ in March; minimum of $6^{\circ} \mathrm{C}$ and maximum of $14^{\circ} \mathrm{C}$ in August, minimum of $17^{\circ} \mathrm{C}$ and maximum of $28^{\circ} \mathrm{C}$ in November, and minimum of $23^{\circ} \mathrm{C}$ and maximum of $35^{\circ} \mathrm{C}$ in January. The humidity range is $77 \%$ and variable is between 72 to $83 \%$ in a year (Brazilian Meteorological Institute).
Blood samples from nine healthy red-footed tortoises ( $C$. carbonaria), not matched by gender and age, were collected in each season of the year, totaling four collections (one per season) and 36 blood samples. All of the clinically healthy animals, determined by clinical examination and medical records, were kept together in an open-air enclosure, being exposed to all environmental conditions. Their daily diet, which they received ad libitum, consisted of vegetables $(60 \%)$, fruits of the season (30\%), protein (totaling 5\% and including commercial feline food, boiled eggs, or ground meat), and mineral supplements (5\%). The study followed the guidelines of the Brazilian National Council for Animal Experimentation Control (CONCEA).

\section{Blood collection}

After being weighed and clinically examined, all the animals were physically restrained, and blood was collected from the jugular vein (vessel of choice for chelonians) [9], or from the dorsal coccygeal vein or from the subcarapacial venous sinus when the first option was not available. Approximately $0.5 \mathrm{~mL}$ of blood was withdrawn from each animal using a 26-gauge needle and syringe or a 22-gauge e needle and syringe for subcarapacial venous sinus collections. All samples with evidence of lymph contamination, observed immediately before blood withdraw in a syringe, were discharged. The blood smears were prepared with fresh blood immediately after collection, and the remainder of the sample was placed in $0.5 \mathrm{~mL}$ lithium heparin microtubes ${ }^{1}$ refrigerated for $2 \mathrm{~h}$ until analysis at the Laboratory of Veterinary Clinical Analyses of Federal University of Rio Grande do Sul (LACVet-UFRGS).

\section{Hematologic analysis}

A total number of red blood cell count (RBC), hematocrit (Hct), hemoglobin value (HGB), mean corpuscular volume (MCV), and mean corpuscular hemoglobin concentration (MCHC) were determined in all samples. Total leukocyte count (WBC) and differential leukocyte count in absolute and relative values were also obtained for all samples. Additionally, a total plasmatic protein (TPP) value was determined by refratometry analysis. RBC and white blood cell were counted manually using a hemocytometer (Neubauer chamber), and the samples were diluted 1:200 with Natt-Herrick's stain [10] and analyzed in duplicate by the same researcher. Hct value was determined by 
the microhematocrit method $(18,840 \times \mathrm{x} g$, for $5 \mathrm{~min})$ while HGB was measured by cyanmethemoglobin in a semi-automated biochemistry analyzer ${ }^{2}$. All the blood smears were stained with Wright's stain ${ }^{3}$ and were counterstained with Diff-quick stain ${ }^{4}$ whenever necessary. Leukocyte differential count was performed manually, in duplicate, by the same researcher using 200 leukocytes under a 100x immersion oil objective. The TPP value was obtained in duplicate by refractometry and the mean of values was considered.

\section{Statistical analysis}

Initially, a descriptive analysis was performed to measure the distribution of the variables in the study. The data distribution was checked for normality using a histogram and, thereafter, the Shapiro-Wilk test, while skewness, kurtosis, and homogeneity were estimated by Levene's test. In case of violation of normality, the data were transformed by $\left\{\log _{10}(x+1)\right\}$ in order to meet the assumptions of the parametric data. Repeated measures ANOVA were used in order to compare the influence of climate variation. For this mater, the colder seasons were collapsed together into one group that holds winter and fall (colds) and the months whit warmer weather spring and summer were grouped as a class called (warm) throughout the year regarding factors such as RBC count, HGB, Hct, MCV, MCHC, heterophil absolute count, eosinophil absolute count, basophil absolute count, monocyte absolute count, lymphocyte absolute count, and TPP. Bonferroni's test was employed as post-hoc analysis. Statistical significance was set as $P \leq 0.05$. The whole statistical process was carried out with R-language, v.3.0.1 (R Development Core Team 2012).

\section{RESULTS}

A total of 27/36 (75\%) samples were collected from the jugular vein, $6 / 36(16.7 \%)$ from the dorsal coccygeal vein, $3 / 36(8.3 \%)$ from the subcarapacial venous sinus and $6 / 36$ samples were contaminated with lymph, discharged and collected from another site. In RBC and WBC values the seasonally were verified. There were statistical differences across seasons in RBC count $(\mathrm{F}=18.2 ; P<0.001)$ [Figure 1 ], HGB values among the seasons $(\mathrm{F}=24.64 ; P<0.001)$, Hct value $(\mathrm{F}=17.11 ; P<0.001)$ and $\mathrm{MCHC}$ values $(\mathrm{F}=7.90 ; P=$ $0.008)$. As to $\mathrm{WBC}$ values, there were statistical differences in heterophil count $(\mathrm{F}=28.01 ; P<0.001)$ [Figure 2]; eosinophil count $(\mathrm{F}=18.86 ; P<0.001)$, basophil count $(\mathrm{F}=17.11 ; P<0.001)$ and monocyte count $(\mathrm{F}=$ 27.21; $P<0.001)$ showed differences between times of the year. Finally, TPP values $(\mathrm{F}=7.36 ; P=0.01)$ were different across the seasons (Figure 3).
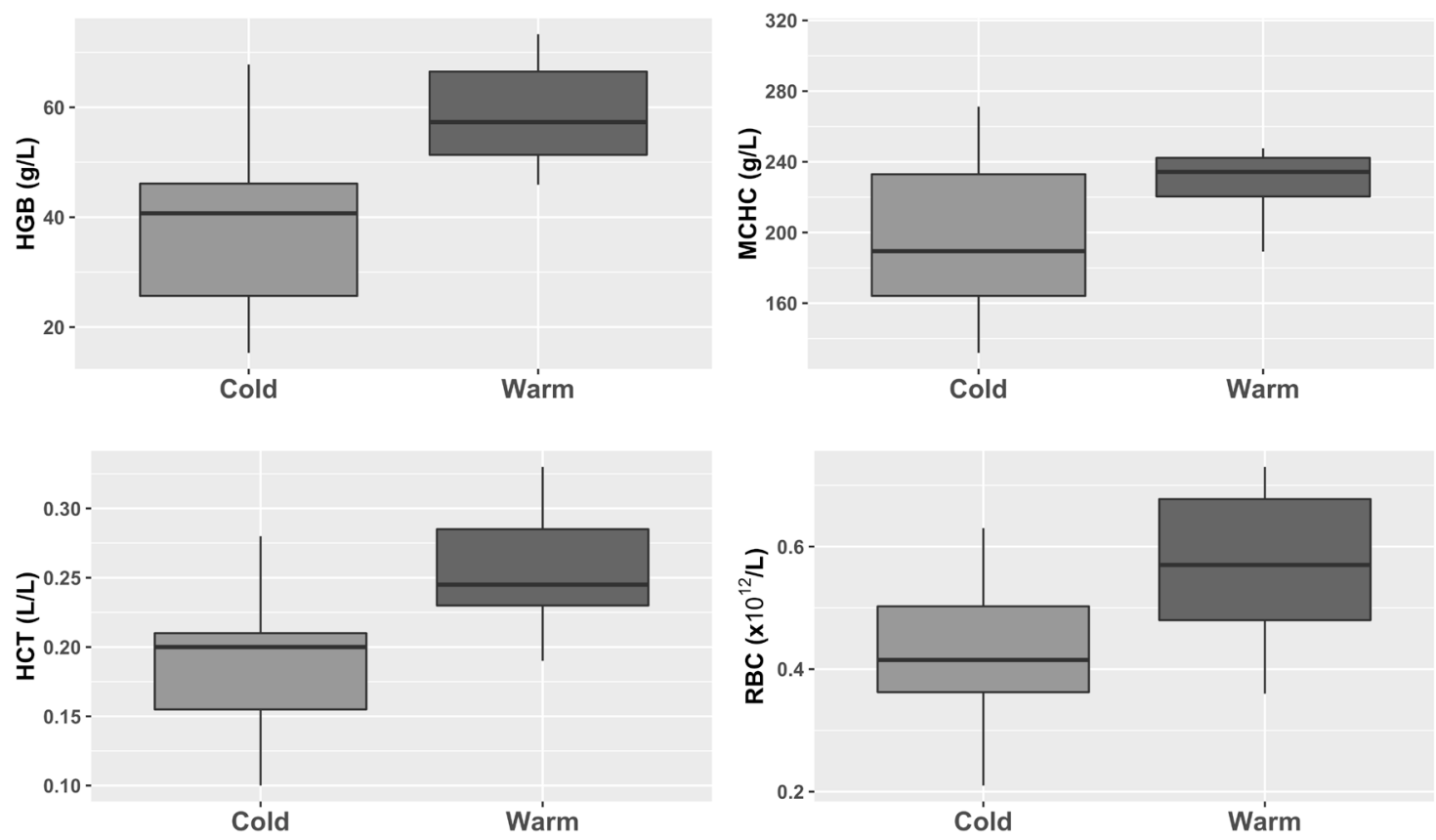

Figure 1. Boxplot of red blood cell values of captive $C$. carbonaria without environmental control in different seasons of the year (cold=winter and fall; warm=summer and spring) in Canoas, Rio Grande do Sul, Brazil. 

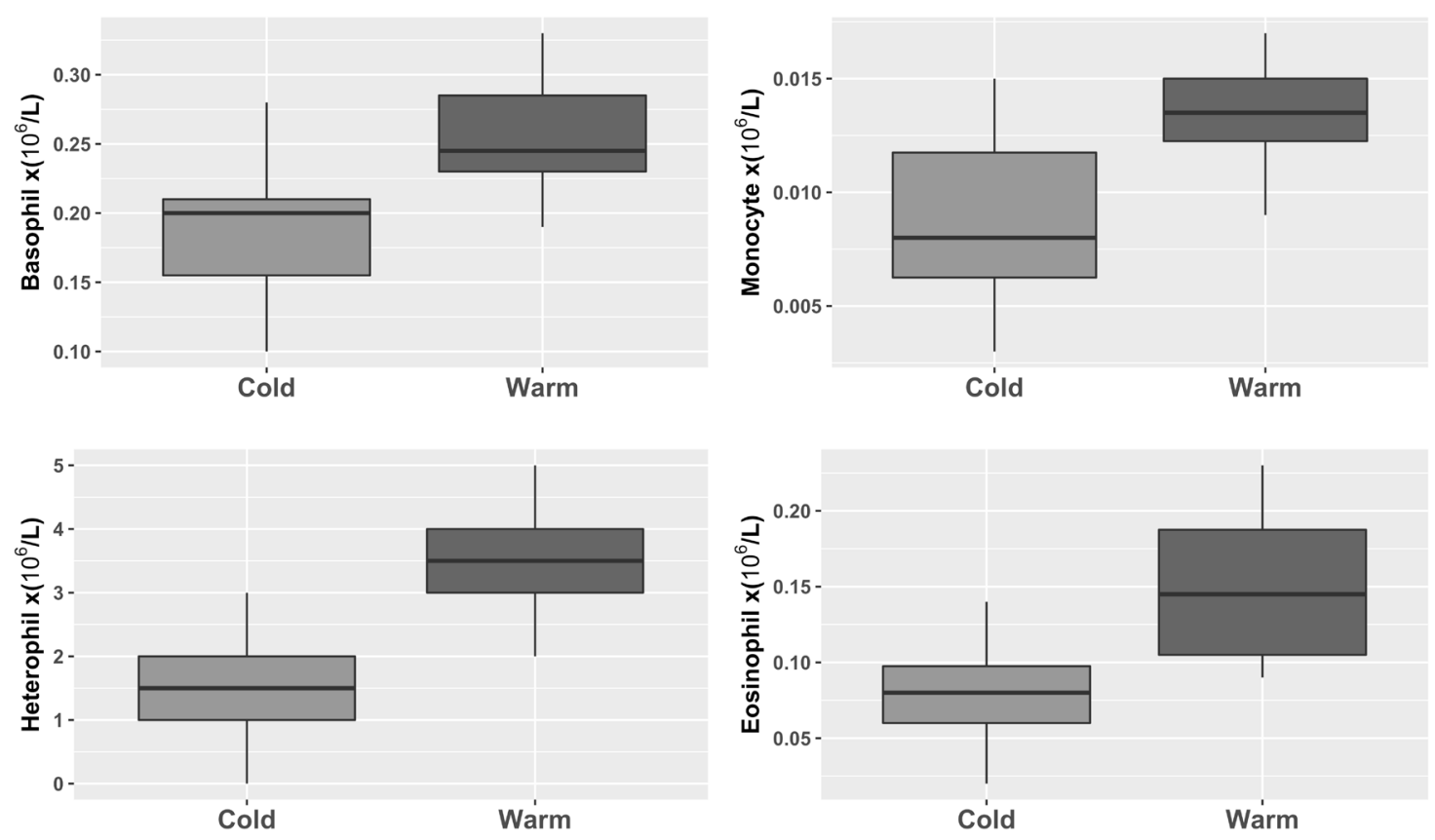

Figure 2. Boxplot of red white cell values of captive C. carbonaria without environmental control in different seasons of the year (cold=winter and fall; warm=summer and spring) in Canoas, Rio Grande do Sul, Brazil.

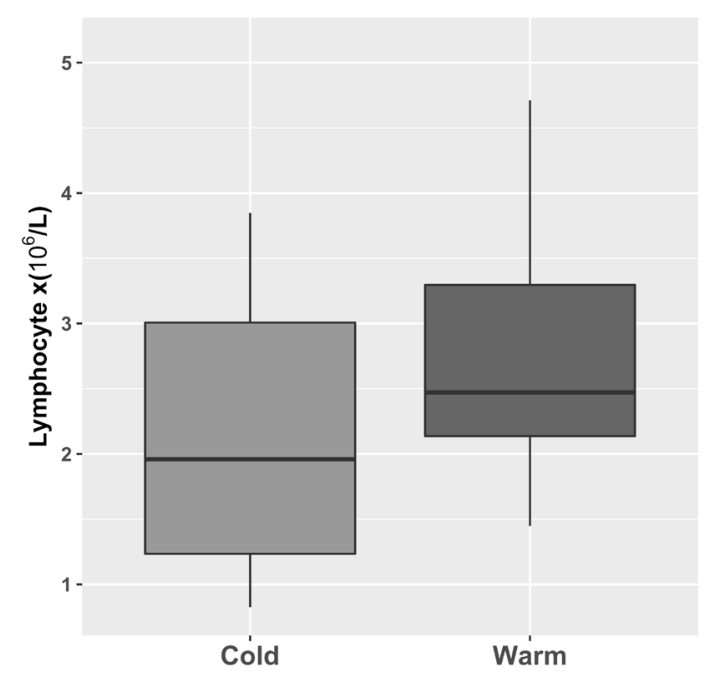

Figure 3. Boxplot of $\log$ (TPP) of captive C. carbonaria without environmental control in different seasons of the year (cold=winter and fall; warm=summer and spring) in Canoas, Rio Grande do Sul, Brazil.

\section{DISCUSSION}

The hematological alterations detected in Chelonoidis carbonaria were similar to those observed in other reptile species $[2,4,5,7,13,15,16]$ but due to the distinct method and management used in those studies on different species, it was not possible to compare the statistical results.

Erythrocyte values yielded significantly higher values in warmer seasons than in the other seasons.
These alterations were also described for captive-bred Geochelone radiata [16], for Boa conscritor kept in captivity in Brazil [7], for Gopherus agassizii desert tortoises in the Mojave Desert, California, United States [11] and recently for Cuora flavomarginata [10]. Free-ranging South American rattlesnakes (Crotalus durissus terrificus) kept in environmentally controlled boxes during the period of analysis had higher Hct, $\mathrm{HGB}$, and whole RBC in winter than in summer [15]. 
These findings confirm the influence of management, mainly concerning thermal control, on reptile metabolism. Hydration status (based on food availability and on water intake) and the greater activity of these species in warm months could explain the elevation of erythrocyte indices in C. carbonaria in summer compared to cold months, taking into account the weather conditions in Brazil [8].

The variation in total WBC count produced by seasons of the year had already been described in snakes, such as in South American rattlesnakes (Crotalus durissus terrificus) [15] and in boas (B. constrictor) [7], in which leukocyte count decreased in winter, without any change in leukocyte differential count. Leukocyte differential count in reptiles may be influenced by several factors such as gender, weight, various diseases, management method, and season of the year. In the sampled animals, there was a significant variation in heterophil, eosinophil, basophil, and monocyte levels across seasons. Most changes observed in cell types show higher values in the hottest month, which coincides with the larger physical activity of this species [6]. This finding was also reported for free-ranging alligator snapping turtles (Macrochelys temminckii), with a higher basophil count in summer than in spring [4] and for desert tortoises (G. agassizii), in which basophil count was lower in winter [5]. Monocyte count was different in G. agassizii [5], G. radiate [16] and Gopherus polyphemus [13], but only the last-named species yielded similar results to those obtained for $C$. carbonaria, with a higher monocyte count in the hottest months. All changes in the analyzed values suggest influence of mild climate changes with the metabolism, and possibly with the immune system, of $C$. carbonaria. This variation in hematological values between the seasons of the year in Brazil must be considered in the interpretation of tests on owned animals or those kept in environmentally preserved areas.

The change in metabolic activity may be one of the causes for alterations in TPP values in reptiles when season of the year is included as a variable. In hibernating species such as G. agassizii [5] the variation in TPP values was attributed to hibernating species when lower food intake led to a decrease in plasma protein levels. In the case of $C$. carbonaria, which does not hibernate, the small sample size was a limitation that did not allow performing additional tests to verify whether TPP values were influenced by metabolic changes across different seasons of the year or by the food intake.

Other limitations of this study were the lack of other climatic variables and of sexing of the analyzed animals. Metabolic changes related to the reproductive activity of females are believed to interfere with hematological values, but it is not possible to categorically state that they influenced the results obtained in this study. Even though samples from a small number of animals (25\%) were collected at a different site, the collection methods might not have influenced the results. In addition, the findings are not consistent with hemolymph contamination because the WBC differential count was not compatible with this artifact and all suspected samples were discharged.

\section{CONCLUSIONS}

In conclusion, despite the small sample size, it was possible to detect variations in hematological reference values that suggest influence of climate on the metabolism of $G$. carbonaria and which should be considered in the interpretation of laboratory tests in clinical practice.

\section{MANUFACTURERS}

${ }^{1}$ Becton, Dickinson and Company (BD). Franklin Lakes, New Jersey, USA.

${ }^{2}$ Labtest Diagnostica. Lagoa Santa, MG, Brazil.

${ }^{3}$ Laborclin Produtos Para Laboratórios Ltda. Pinhais, PR, Brazil.

${ }^{4}$ Newprov Produtos Para Laboratórios Ltda. Pinhais, PR, Brazil.

Ethical approval. All applicable international, national and/ or institutional guidelines for the care and use of animals were followed.

Declaration of interest. The authors declare that they have no conflict of interest. The authors alone are responsible for the content and writing of paper.

\section{REFERENCES}

1 Boyer T.H. \& Boyer D.M. 2006. Turtles, Tortoises and Terrapins. In: Mader D.R. (Ed). Reptile Medicine and Surgery. 2nd edn. Saint Louis: Saunders Elsevier, pp.78-99.

2 Bryant G.L., Fleming P.A., Twomey L. \& Warren K.A. 2012. Factors affecting hematology and plasma biochemistry in the Southwest carpet python (Morelia spilota imbricata). Journal of Wildlife Diseases. 48(2): 282-294. 
3 Campbell T.W. 2012. Hematology of Reptiles. In: Thrall M.A., Weiser G., Allison R. \& Campbell T.W. (Eds). Veterinary Hematology and Clinical Chemistry. 2nd edn. Ames: Wiley-Blackwell, pp.277-297.

4 Chaffin K., Norton T.M., Gilardi K., Poppenga R., Jensen J.B., Moler P., Cray C., Dierenfeld E.S., Chen T., Oliva M., Origgi F.C., Gibbs S., Mazzaro L. \& Mazet J. 2008. Health assessment of free-ranging alligator snapping turtles (Macrochelys temminckii) in Georgia and Florida. Journal of Wildlife Diseases. 44(3): 670-686.

5 Christopher M.M., Berry K.H., Wallis I.R., Nagy K.A., Henen B.T. \& Peterson C.C. 1999. Reference intervals and physiologic alterations in hematologic and biochemical values of free-ranging desert tortoises in the Mojave desert. Journal of Wildlife Diseases. 35(2): 212-238.

6 Cubas P.H. 2007. Chelonia (Tartaruga, Cagado, Jabuti). In: Cubas Z.S., Silva J.C.R. \& Catão-Dias J.L. (Eds). Tratado de Animais Selvagens. São Paulo: Roca, pp. 86-119.

7 Machado C.C., Silva L.F., Ramos P.R. \& Takahira R.K. 2006. Seasonal influence on hematologic values and hemoglobin electrophoresis in Brazilian Boa constrictor amarali. Journal of Zoo and Wildlife Medicine. 37(4): 487-491.

8 Murray M.J. 2006. Cardiopulmonary anatomy and physiology. In: Mader D.R. (Ed). Reptile Medicine and Surgery. 2nd edn. St. Louis: Saunders Elsevier, pp.124-134.

9 Nardini G., Leopardi S. \& Bielli M. 2013. Clinical hematology in reptilian species. Veterinary Clinics of North America: Exotic Animal Practice. (16): 1-30.

10 Yang P.Y., Yu P.H., Wu S.H. \& Chie C.H. 2014. Seasonal hematology and plasma biochemistry reference range values of the yellow-marginated box turtle (Cuora flavomarginata). Journal of Zoo and Wildlife Medicine. 45(2): 278-286.

11 Rovira A. 2010. Hematology of Reptiles. In: Weiss D.J. \& Wardrop K.J. (Eds). Schalm's Veterinary Hematology. 6th edn. Ames: Wiley-Blackwell, pp.1004-1012.

12 Stacy N.I., Alleman A.R. \& Sayler K.A. 2011. Diagnostic hematology of reptiles. Clinics in Laboratory Medicine. 31(1): 87-108.

13 Taylor R.W. \& Jacobson E.R. 1982. Hematology and serum chemistry of the gopher tortoise Gopherus polyphemus. Comparative Biochemistry and Physiology. 72(2): 425-428.

14 Tosunoglu M., Yilmaz N. \& Gul C. 2011. Effects of varying ecological conditions on the blood parameters of freshwater turtles in Canakkale (Turkey). Ekoloji. 20(78): 7-12.

15 Troiano J.C., Vidal J.C., Gould J. \& Gould E. 1997. Haematological reference intervals of the South American rattlesnake (Crotalus durissus terrificus, Laurenti, 1768) in captivity. Comparative Haematology International. 7(2): 109-112.

16 Zaias J., Norton T., Fickel A., Spratt J., Altman N.H. \& Cray C. 2006. Biochemical and hematologic values for 18 clinically healthy radiated tortoises (Geochelone radiata) on St Catherines Island, Georgia. Veterinary Clinical Pathology Journal. 35(3): 321-325. 